\title{
Category norm data and relationships with lexical frequency and typicality within verb semantic categories
}

\author{
Christopher Plant · Janet Webster • Anne Whitworth
}

Published online: 7 February 2011

(C) Psychonomic Society, Inc. 2011

\begin{abstract}
The aim of the present study was to expand the scope of category norm and typicality data to include verbs for use when investigating semantic memory in fields such as linguistics, psychology, and aphasiology. Two experiments were conducted. In the first, participants were asked to list verbs within 10 semantic categories (e.g. breaking, cleaning, cooking, etc.) and 10 noun categories (e.g. animals, fruit, tools, etc.). In the second experiment, participants were asked to rate the typicality of verbs within 8 of the previously investigated verb categories. Although participants listed fewer verbs in verb categories than nouns in noun categories, the overall patterns with regard to correlation analyses between production frequency, mean rank of responses, lexical frequency, and typicality were consistent with those observed in noun categories. These patterns are also consistent with those observed in previous research. Potential similarities and differences between nouns and verbs, as well as future applications of such data, are discussed.
\end{abstract}

Keywords Actions · Categorisation · Semantic memory · Typicality · Verbs

This research was supported by Economic and Social Research Council (ESRC) Grant S/F02441X/1 awarded to the first author. Further data related to this study which is not reported directly in the present article is available to interested readers via correspondence with the first author. The authors thank the volunteers for their participation in this study. We are also grateful to the three reviewers who provided helpful comments in improving an earlier version of the manuscript

C. Plant $(\varangle) \cdot$ J. Webster $\cdot$ A. Whitworth

School of Education, Communication \& Language Sciences,

Newcastle University,

King George VI Building, Queen Victoria Road,

Newcastle upon Tyne, NE1 7RU, UK

e-mail: c.s.plant@ncl.ac.uk

\section{Background}

Research into semantic and lexical memory relies on the existence of valid normative data. Such data serve as a benchmark against which further research can make comparisons and are often vital in designing experiments by aiding in the selection of experimental stimuli. In addition, the normative data themselves often illuminate intriguing aspects of linguistic and psychological behaviour. This article presents the findings of preliminary studies to extend the scope of normative data into the domain of verbs - specifically, in relation to semantic categorisation and typicality.

A prominent example of normative data was provided by Battig and Montague (1969), who presented category norms for 56 categories, including such categories as precious stones, four-footed animals, carpenter's tools, and so on. Participants were given $30 \mathrm{~s}$ to write down as many objects within each category as possible. Along with the actual responses given within each category, Battig and Montague reported a host of associated statistics, including the production frequency (sometimes called category association strength/dominance) of each response in each category (i.e. the number of participants who listed each response), the number of participants who listed each response first within each category, and the mean rank position of each response within each category. They also reported correlational analyses between these measures, which suggested a strong relationship between production frequency and mean rank within categories; that is, the responses that were given by most participants were also listed earlier.

These norms offered other researchers a powerful resource that was psychologically valid, having been generated directly by speakers. Such is the continued 
impact of the Battig and Montague (1969) category norms that Van Overschelde, Rawson, and Dunlosky (2004) reported that they had been cited over 1,600 times in over 220 different journals and that the continued use of such data validated the need for an updated and expanded category norm collection.

One particular area where the Battig and Montague (1969) norms have been utilised is in research investigating the organisation and structure of semantic memory. For example, work by Rosch and colleagues (e.g. Mervis, Catlin, \& Rosch, 1976; Rosch, Mervis, Gray, Johnson, \& Boyes-Braem, 1976) provided insights into the categorical nature of semantic memory. Such work was developed further with investigation into how semantic memory can be further fractionated. For example, within research in the field of aphasiology, there have been investigations into possible dissociations between living/non-living, biological/non-biological, and animate/inanimate objects (e.g. Caramazza \& Shelton, 1998; Riddoch \& Humphreys, 1987), and then also between small manipulable objects and large objects (e.g. Warrington \& McCarthy, 1987). All such research relies on category norm data to lend validity both to the experimental design and methodologies, as well as to their original motivations, and in drawing conclusions.

A possible issue of contention with category norm data is the assumption that such data are a valid representation of pre-linguistic processes (i.e. semantic processing). For example, the data generated by category norm tasks essentially amount to a list of words, most usually a list of nouns. It has then been assumed that these lexicalised representations share a one-to-one mapping between semantic/conceptual representations. Therefore, the noun cat in the lexical domain is assumed to map onto the object cat in the semantic/conceptual domain. Although caution has been advised in interpreting such normative data in this way (e.g. McRae, Cree, Seidenberg, \& McNorgan, 2005), it is also acknowledged that such norms do offer useful insights into the semantic/conceptual domain. In the context of the present article, this issue has implications for the terminology employed. For example, how normative data are being interpreted may be indicated by whether one uses the term word or the term concept. Similarly, one may choose to use the terms noun and verb, or object and action. In the present article, these terms will be assumed to be interchangeable (i.e. as having a one-to-one mapping) since, for the most part, the verbs discussed and elicited here relate to actions (as opposed to states) and the nouns discussed and elicited here relate to objects or entities (as opposed to actions or events).

In addition to category norms, an important adjunct is data relating to the typicality of responses within categories (e.g. Hampton \& Gardiner, 1983; Rosch \& Mervis, 1975). Typicality — or sometimes, prototypicality or good- ness of fit-refers to a measure of how representative an individual response is of the category as a whole. For example, oranges and apples are perceived as being more typical and, hence, more representative of the category fruit than are tomatoes and olives.

Typicality has been argued to be a valid structural principle in semantic memory. Concepts are suggested to fall along a typicality gradient ranging from most typical concepts (within a category) to least typical, or atypical. It is also accounted for in theories of semantic memory as a consequence of a concept's featural decomposition (e.g. Smith, Shoben, \& Rips, 1974).

Typicality has been shown, in some respects, to be dissociable from lexical frequency (i.e. the frequency with which a word appears in the language in general; e.g. Kučera \& Francis, 1967). Mervis et al. (1976) found that within eight categories, typicality significantly correlated with production frequency, but not with lexical frequency. Also, production frequency correlated with lexical frequency in only two of the eight categories. Therefore, it was concluded that typicality was the most reliable predictor of performance in the category-listing task.

A similar finding was also observed by Hampton and Gardiner (1983), who performed correlation analyses between measures of typicality, production frequency, and familiarity of objects in 12 categories. Although all the correlations were significant, the strongest relationships were observed between typicality and production frequency (mean correlation of $r=-.76$ ). This was especially the case for categories not involving creatures (i.e. birds, fish, or insects), where typicality and familiarity were both strongly associated with production frequency.

Typicality also affects performance in a number of other behavioural paradigms. Typical concepts are responded to more quickly than atypical items within psychological tasks using semantic decisions (e.g. verifying category membership), lexical decisions, and naming. Typicality is also a potentially important factor to consider when designing treatment studies in aphasia, since it has been suggested that treatment has the potential to be more effective when targeted at atypical concepts (e.g. Kiran \& Thompson, 2003).

Currently, category norms and typicality data are almost exclusively restricted to object concepts (i.e. nouns), and there has been little extension into the domain of actions (i.e. verbs). Recently, however, attention has turned to the investigation of how verbs are represented and retrieved from within semantic memory. For example, in the work of Vigliocco, Vinson, and colleagues (e.g. Vigliocco, Vinson, Lewis, \& Garret, 2004; Vinson, Vigliocco, Cappa, \& Siri, 2003) simulating semantic representations of both nouns and verbs has been looked at, using data obtained from semantic feature norms. Similarly, there has been increased attention in aphasiology to better utilising semantic theory 
associated with verbs in order to better inform assessment and treatment of participants with language impairment (e.g. Conroy, Sage, \& Lambon Ralph, 2006). However, without the necessary normative data underlying such investigations, the validity of any findings is open to question.

There have been 'small-scale' attempts at gaining normative data for verb semantic categories. For example, Hemeren (1996) reported data where participants wrote down "actions that involve some kind of bodily activity that can easily be recognised when seen and can be visualised as a mental image" (p. 44; Hemeren's italics). The methodology is therefore comparable to those previously employed in gaining normative data for noun categories. Also, similar to previous findings in noun research (i.e. Battig \& Montague, 1969), production frequency was found to correlate significantly with mean rank within the category $(r=-.70)$, suggesting that the verbs listed by most participants were listed earlier. In this research, however, only a single category was looked at, and one which was not as restrictive as those employed in noun research.

There are other resources available for researchers to draw upon which are attempts to categorise and classify verbs according to semantic relations (e.g. Levin, 1993). However, the drawback to such approaches is that they are post hoc in nature and often tend to rely heavily on a syntactic analysis of how verbs are distributed in written language samples. Such resources may therefore lack the psychological validity required for occasions on which research is conducted using online behavioural measures (e.g. measuring response times), since this may not be an accurate representation of how verbs are stored and accessed in semantic memory.

This article reports the findings of preliminary research that extends category norm and typicality data into the domain of verbs (i.e. action concepts). In addition to presenting the methodology and results of this research, the data themselves are presented in appendices to allow readers access to a set of valid speaker-generated norms for use when working with verbs.

Data collection was divided between two experiments. The aim of the first was to establish valid category norms for 10 verb semantic categories and to make quantitative comparisons with parallel norms collected for 10 noun semantic categories. The aim of the second experiment was to establish typicality ratings for verbs within 8 of the 10 normed verb categories.

\section{Experiment 1: establishing category norms}

Method

Participants A total of 35 participants completed the experiment. This sample included 13 males and 22 females
$(M$ age $=23.1$ years, $S D=7.9$, range $=18-57)$. All the participants were enrolled in university degree programmes and were native English speakers. Participants were recruited after responding to email invitations, and all gave signed consent and either were paid for taking part or were entered into a cash/voucher prize draw.

Stimuli selection The experimental stimuli to be used as categories were selected by referring to WordNet (e.g. Miller \& Fellbaum, 1991). WordNet is a lexical database that employs relational semantic principles (i.e. hyponymy in the case of nouns and troponymy in the case of verbs) in representing hierarchical organisation for both nouns and (action) verbs. Although the relations of hyponymy and troponymy are not qualitatively the same, they do establish the same entailment relations. For example, they establish hierarchical relations so that for nouns, one can state that 'an apple is a type of fruit', where fruit is represented at a higher hierarchical level than is apple. Conversely, one cannot state that 'a fruit is a type of apple'. Similarly, with verbs, one can state that 'washing is a way, or manner, of cleaning something' where cleaning is represented at a higher hierarchical level than is washing Again, one cannot state that 'cleaning is a way, or manner, of washing something'.

Ten verbs were selected to serve as different semantic categories. These were breaking, cleaning, cooking, cutting, hitting, jumping, making, running, talking, and walking. These verbs appeared at the level above the most densely populated hierarchical level within the action verb subsection of the WordNet database. Therefore, they were assumed to represent general categories of action which would elicit responses that were semantically diverse yet still clearly related to the category and also to each other.

The ten noun categories were animals, birds, clothes, fruit, furniture, musical instruments, sports, tools, transport, and vegetables. These were consistent with categories employed in previous research (e.g. Hampton \& Gardiner, 1983; Rosch et al., 1976) and were again assumed to have the potential to elicit nouns which were semantically diverse yet still related to the category.

Procedure Participants were seen in groups, and each was given a workbook to complete. Written instructions stated that they would read a series of sentences that would ask them to list words that were related to a specified category (e.g. 'write down as many different types of game as you can think of', or 'write down as many different ways of moving something as you can think of'). They were instructed to keep their responses to a single word or as short as possible. Participants were shown two completed examples for the categories game and moving, each with eight example responses (e.g. football, chess, cards, and so on, and pushing, pulling, rolling, and so on). 
Participants were given $2 \mathrm{~min}$ to list responses within each category. Each category was presented on a different page of the workbook, and participants were instructed not to turn the page and begin a new category until the experimenter announced that $2 \mathrm{~min}$ had expired. There were 20 numbered spaces on each page for participants to write responses. They were instructed that they were not required to fill all spaces, just as many as they could within the time. However, if they could list more than 20 responses, they were told to do so in an orderly manner at the bottom of the page.

Participants listed responses for all 20 categories in one of two counterbalanced workbooks. The order of categories was randomised, although the presentation alternated between noun and verb categories. The order of categories in one workbook was reversed for the second to counterbalance any possible effects of fatigue that might have occurred as the 40-min experimental session progressed.

\section{Data preparation}

Before analysis, the raw data were subjected to a number of cleanup processes. An initial phase involved standardising spelling across the data. Second, plurality and tense were standardised where no discrimination was made between different morphological realisations of the same base lemma. For example, both cat and cats were standardised and counted as examples of the same response in the same way that drop and dropping were. The only occasions on which this was not the case were when it was ambiguous as to whether the participant had intended the response as a noun or a verb - for example, where a response was written in a form ambiguous between a noun and a verb in infinitive form (e.g. soap) and where no other participant had written the response in a corresponding finite form (e.g. soaping). In such cases the ambiguous response was excluded from analysis on the basis of word class (e.g. coded as a noun given within a verb category). Third, elimination of repetition was carried out.

Some participants listed two or more responses in a single response space in the workbooks. This was generally done when participants felt responses were synonymous or very similar (e.g. sultanas/raisins). All such responses were counted individually. Any responses that were repetitions of previous responses in the same category list, or which repeated the category itself, were excluded. Finally, word class was standardised.

To ensure that only nouns were counted within noun categories and only verbs were counted within verb categories, responses were excluded on the basis of word class. These included responses written as prepositional phrases (e.g. with a hammer, in the oven, for pleasure, and so on), adverbs, and adjectives (e.g. quickly, strongly, hard, fast, and so on), nouns which were listed in verb categories, and verbs which were listed in noun categories (n.b. some obvious exceptions were made-for example, in the category of sports, which included a number of response written as verbs, such as running, swimming, horse riding, and so on).

No other criteria were applied to the data. Responses at differing levels of categorisation were included and counted as separate responses (e.g. chair, rocking chair, dining chair; frying, deep frying, stir frying; and so on). Adaptation of the raw data was kept to a minimum even where responses appeared synonymous. For example, both vacuum and hoover were counted as separate responses in the category of cleaning, primarily because some participants had listed both. However, some differences in vocabulary were combined; for example, eggplant was subsumed and combined with aubergine because eggplant was listed only once and was presumed to be a lexical variation, since aubergine was not also given by the same participant. A more straightforward example was with aeroplane and plane, which were also subsumed.

\section{Results}

Data preparation Following initial 'cleanup' processes (e.g. standardising spelling, plurality, tense, etc.), 3,313 responses were listed across all 10 verb categories across all participants. Following application of the exclusion criteria, 738 responses were excluded, leaving 2,575 responses, which were subjected to further analysis. In comparison, 6,412 responses were listed across the 10 noun categories, with just 42 of these being excluded, leaving 6,370 responses for further analysis.

Within verb categories, the majority of exclusions were adverbs/adjectives (53.3\% of total exclusions), but there were also a substantial number of nouns (23.4\%) and prepositional phrases $(21.3 \%)$. The remainder were classified as repetitions $(1.26 \%)$ or 'other' $(4.06 \%)$, where the verb was applied in a different sense than that intended (e.g. to break up with someone, to make friends).

A large proportion of exclusions were from the categories of running (20.2\% of total exclusions), talking (18.6\%), walking (16.2\%), and cutting (14.7\%). The greatest number of exclusions was for adverb/adjective responses given within the category talking (e.g. loudly, quietly), which accounted for $12.6 \%$ of all exclusions in verb categories.

Within noun categories, the majority of exclusions were verbs given within the category of transport (e.g. walking, jumping), which accounted for $69 \%$ of the total exclusions in noun categories. Most other exclusions were repetitions $(26.2 \%)$, which were spread across 6 of the 10 categories, with the remaining exclusions being adverb/adjectives $(4.76 \%)$. 
It is interesting to draw attention to the fact that exclusions that occurred between noun and verb categories were qualitatively different. Whereas the majority of responses excluded from noun categories were on the basis of word class or repetition, the majority of exclusions in verb categories were, in essence, expressing subtle semantic distinctions from the category verb. For example, a number of responses within the category talking offered slight modifications to the manner in which one might talk (e.g. loudly, softly, quietly). Similarly, within the categories walking and running, excluded responses tended to express directionality (e.g. backwards, forwards, sideways) or manner (e.g. fast, slow). Although such responses do express shades of semantic representation, the justification for excluding them within the present analysis is that they tended to function as modifiers and are not idiosyncratic actions that can be expressed as a single verb; they do not, therefore, serve to differentiate one particular action verb from another. However, since exclusions are potentially insightful, exclusions with a high frequency (given by 5 or more participants) accompany the data tables in Appendix A.

Effect of gender Since gender differences had been observed in investigations of the organisation and retrieval of words from semantic memory (e.g. Capitani, Laiacona, \& Barbarotto, 1999; Laiacona, Barbarotto, \& Capitani, 2006), a preliminary analysis was conducted to investigate whether gender affected quantitative properties of the data. This was necessary due to there being an over-representation of female participants in the total sample, which might bias the data if such differences were present. The data from 13 female participants were selected at random and paired with the data from the 13 male participants. The data were then compared using independent samples $t$-tests (two-tailed) with the significance level set at $p<.05$. There were no significant differences between male and female participants in terms of the total number of responses listed, $t(24)=$ $1.146, p=.263, d=0.65$, the total number of verbs listed, $t$ (24) $=1.395, p=.176, d=0.55$, or the total number of nouns listed, $t(24)=0.695, p=.442, d=0.28$.

Analysis was also carried out at the level of individual categories. Of the verb categories, there were significant differences between male and female participants for the categories breaking, $t(24)=2.467, p=.021, d=0.9$, and walking, $t(24)=2.137, p=.043, d=0.84$, where females listed more responses than did males. There were no significant differences observed within noun categories, although furniture, $t(24)=2.042, p=.052, d=0.81$, and vegetables, $t(24)=1.917, p=.067, d=0.76$, showed trends towards significance, again with females listing more responses than did males. No other comparisons showed significant differences between male and female participants. Despite there being some significant differences between males and females, these were not considered to be influencing the task as a whole, and therefore, for subsequent analysis, data from all 35 participants were pooled.

Effect of presentation list A further preliminary analysis involved quantitative comparison of the data produced from the two presentation lists. This can, to some extent, be an indicator of the reliability of the data. Since two administration lists were employed, primarily to counteract any possible effects of fatigue in the 40-min experimental session, it may be possible that some differences were present-for example, between categories that were presented earlier in one list and later in the other list. This analysis was carried out with the data from 34 participants, with 1 participant's data being randomly excluded to ensure an equal number of data for each presentation list. There were no significant differences between the two presentation lists in terms of the total number of responses listed, $t$ $(32)=0.658, p=.515, d=0.23$, the number of verbs listed, $t(32)=0.091, p=.928 . d=0.33$, or the total number of nouns listed, $t(32)=0.951, p=.349, d=0.03$.

Analysis was additionally conducted at the level of individual categories. The only significant difference observed was within the walking category, $t(32)=3.644$, $p=.001, d=1.25$, where participants completing list A (where walking was the 15 th category completed) listed significantly more verbs than did participants completing list B (where walking was the 6th category completed). No other comparisons approached significance.

Effect of word class Analysing the data from all 35 participants, a significant difference was seen between the mean number of verbs and nouns listed (paired samples $t$ test; $t(24)=22.261, p<.001, d=4.42$, one-tailed), where there were more nouns $(M=182.03, S D=29.942)$ listed than verbs $(M=73.54, S D=19.137)$ across all the respective categories.

Category analysis Tables 1 and 2 present descriptive statistics for each category. These include: the mean number of responses listed $(M)$ and the respective standard deviations ( $S D s)$, the range of responses listed (Range), and the number of different responses listed (Different). In Appendix A, tables present the qualitative data within each verb category, including the actual responses given ordered by their production frequency (i.e. the number of participants listing the response). For responses with a production frequency of 3 or higher, the mean rank position of the response (i.e. the mean ordinal position that participants tended to give each response; e.g. the first response given within a category was assigned the rank of 1 , the second response a rank of 2, and so on) is also given. Mean rank 
Table 1 Descriptive statistics for verb categories

\begin{tabular}{lrlll}
\hline & $M$ & $S D$ & Range & Different \\
\hline Breaking & 9.09 & 3.576 & $3-17$ & 83 \\
Cleaning & 10.20 & 2.898 & $5-16$ & 67 \\
Cooking & 10.37 & 3.379 & $6-20$ & 60 \\
Cutting & 5.60 & 3.070 & $0-12$ & 58 \\
Hitting & 7.46 & 3.689 & $0-14$ & 76 \\
Jumping & 5.97 & 2.717 & $1-13$ & 48 \\
Making & 8.94 & 3.307 & $3-16$ & 90 \\
Running & 3.11 & 1.659 & $0-7$ & 25 \\
Talking & 7.00 & 4.332 & $0-14$ & 82 \\
Walking & 5.80 & 3.653 & $0-14$ & 68 \\
\hline
\end{tabular}

was calculated according to the number of participants who actually listed the response, rather than as an average across all 35 participants. The number of participants who listed each response first within a category is given. Finally, verbs with a production frequency of 2 are also listed, whereas those with a production frequency of 1 are not listed here. The qualitative data within noun categories are not presented here, since such resources are readily available and the primary qualitative concern here is with verb categories.

Correlation analysis: production frequency with mean rank An investigation into the internal structure of the categories was conducted between measures of production frequency and mean rank, using a correlational analysis. This was carried out for all the responses within each category that had a production frequency of 3 or more. In calculating all correlation coefficients, Spearman's coefficient is reported in favour of Pearson's coefficient, since this makes fewer assumptions about the distribution and variances within the data and was considered to be more appropriate for this preliminary analysis of verb semantic categories.

Table 2 Descriptive statistics for noun categories

\begin{tabular}{lcrrc}
\hline & $M$ & $S D$ & Range & Different \\
\hline Animals & 22.89 & 5.229 & $9-33$ & 163 \\
Birds & 18.77 & 4.995 & $5-28$ & 122 \\
Clothes & 21.26 & 3.744 & $15-31$ & 117 \\
Fruit & 19.46 & 3.845 & $11-29$ & 69 \\
Furniture & 14.60 & 3.283 & $9-21$ & 99 \\
Musical instruments & 19.14 & 4.038 & $11-30$ & 73 \\
Sports & 20.11 & 3.385 & $13-30$ & 120 \\
Tools & 13.14 & 3.318 & $6-20$ & 111 \\
Transport & 15.94 & 4.419 & $8-23$ & 106 \\
Vegetables & 16.71 & 3.667 & $7-25$ & 71 \\
\hline
\end{tabular}

Table 3 Correlational analysis, production frequency, and mean rank (verbs)

\begin{tabular}{llc}
\hline Category & $\begin{array}{l}\text { Spearman's } \\
\text { Coefficient }\left(r_{\mathrm{s}}\right)\end{array}$ & $\begin{array}{l}\text { Number of } \\
\text { Observations }(N)\end{array}$ \\
\hline Breaking & $-.483^{* *}$ & 30 \\
Cleaning & $-.559^{* *}$ & 30 \\
Cooking & $-.629^{* *}$ & 28 \\
Cutting & $-.513^{*}$ & 18 \\
Hitting & $-.459^{*}$ & 26 \\
Jumping & $-.785^{* *}$ & 18 \\
Making & $-.408^{*}$ & 31 \\
Running & -.754 & 6 \\
Talking & -.345 & 21 \\
Walking & -.338 & 25 \\
\hline
\end{tabular}

$* p<.05$ (two-tailed)

$* * p<.01$ (two-tailed)

Tables 3 and 4 present the correlation statistics for production frequency and mean rank associated with each category. The only categories that failed to produce significant relationships between production frequency and mean rank were running, talking, and walking.

Correlation analysis: production frequency and mean rank with lexical frequency An additional correlational analysis was conducted using the measures obtained here with measures of lexical frequency. The measures of lexical frequency employed were the frequency counts from Kučera and Francis (1967) and also the CELEX database (Coltheart, 1981), which gives a lemma frequency count per million words of written English. Tables 5 and 6 present

Table 4 Correlational analysis, production frequency, and mean rank (nouns)

\begin{tabular}{lcc}
\hline Category & $\begin{array}{l}\text { Spearman's } \\
\text { coefficient }\left(r_{\mathrm{s}}\right)\end{array}$ & $\begin{array}{l}\text { Number of } \\
\text { observations }(N)\end{array}$ \\
\hline Animals & $-.572^{* *}$ & 65 \\
Birds & $-.274^{*}$ & 63 \\
Clothes & $-.534 * *$ & 51 \\
Fruit & $-.382 * *$ & 45 \\
Furniture & $-.543 * *$ & 41 \\
Musical instruments & $-.641 * *$ & 46 \\
Sports & $-.527 * *$ & 58 \\
Tools & $-.614 * *$ & 36 \\
Transport & $-.547 * *$ & 48 \\
Vegetables & $-.734 * *$ & 39 \\
\hline$* p<.05$ (two-tailed) & & \\
$* * p<.01$ (two-tailed) & &
\end{tabular}


Table 5 Correlational analysis $\left(r_{\mathrm{s}}\right)$ with lexical frequency (verbs)

Freq $=$ Production frequency;

Rank $=$ Mean rank;

$\mathrm{K}-\mathrm{F}=$ Kučera and Francis

(1967) frequency count;

$\mathrm{CEL}=\mathrm{CELEX}$ frequency count .

${ }^{*} p<.05$ (two-tailed)

$* * p<.01$ (two-tailed)

\begin{tabular}{lccccc}
\hline Category & Freq $\times$ Rank & Freq $\times$ K-F & Freq $\times$ CEL & Rank $\times$ K-F & Rank $\times$ CEL \\
\hline Breaking (18) & $-.687^{* *}$ & -.276 & -.181 & .271 & .077 \\
Cleaning (14) & $-.840^{* *}$ & .173 & $.537^{*}$ & -.300 & $-.550^{*}$ \\
Cooking (11) & $-.808^{* *}$ & $.654^{*}$ & .110 & -.314 & .183 \\
Cutting (9) & $-.707^{*}$ & .312 & .213 & .288 & -.017 \\
Hitting (14) & $-.554^{*}$ & $-.726^{* *}$ & -.172 & .337 & .359 \\
Jumping (5) & $-1.000^{* *}$ & -.158 & .205 & .158 & -.205 \\
Making (16) & -.237 & -.414 & .311 & .421 & -.003 \\
Running (4) & -.949 & -.778 & -.738 & .738 & .600 \\
Talking (11) & -.397 & $-.724 *$ & .243 & .132 & -.564 \\
Walking (7) & $-.929 * *$ & .143 & .071 & -.036 & -.036 \\
\hline
\end{tabular}

the results of these correlation analyses. Since a number of nouns and verbs under investigation were not included within the Kučera and Francis and CELEX databases, correlations were conducted with only those nouns and verbs for which full frequency data were available. The number of observations on which correlations are based is indicated in parentheses with the category name. Due to the differential numbers of observations, correlations between production frequency and mean rank were again calculated in order to allow for comparative analysis.

For both verb and noun categories, the only relationship which consistently reached significance was the production frequency by mean rank correlation, which did so for 7 out of 10 verb categories and all 10 noun categories.

\section{Experiment 2: typicality rating}

Method

Participants A total of 102 participants completed the experiment. This sample included 34 males and 68 females $(M$ age $=20.9$ years, $S D=4.39$, range $=18-58)$. All the participants were enrolled in university degree programmes and were native English speakers. Participants were recruited after responding to email invitations and were entered into a cash/voucher prize draw for taking part.

Stimuli selection Responses from eight verb categories were used. These were drawn from the categories breaking, cleaning, cooking, cutting, hitting, making, talking, and walking. The categories of jumping and running were excluded for this experiment due to the limited number of responses given within them in Experiment 1.

Within the eight categories, all verbs with a production frequency of 3 or greater in Experiment 1 were included in this experiment. This totalled 209 verbs for which typicality ratings were obtained. The number of verbs drawn from each category ranged from 18 (cutting) to 31 (making).

Procedure Typicality ratings were collected via a Webbased survey tool (www.surveymonkey.com). Participants were instructed that they were to judge how typical certain actions were in relation to a more general category. To elucidate this point, participants were given the following standard passage to consider regarding how typicality is utilised within the domain of objects:
Table 6 Correlational analysis $\left(r_{\mathrm{s}}\right)$ with lexical frequency (nouns)

Freq $=$ production frequency;

Rank = mean rank; $\mathrm{K}-\mathrm{F}=$

Kučera and Francis (1967)

frequency count; $\mathrm{CEL}=\mathrm{CELEX}$

frequency count.

${ }^{*} p<.05$ (two-tailed)

$* * p<.01$ (two-tailed)

\begin{tabular}{lccccc}
\hline Category & Freq $\times$ Rank & Freq $\times$ K-F & Freq $\times$ CEL & Rank $\times$ K-F & Rank-CEL \\
\hline Animals (43) & $-.593^{* *}$ & $.520^{* *}$ & $.704^{* *}$ & $-.518^{* *}$ & $-.558^{* *}$ \\
Birds (19) & $-.559^{*}$ & $.516^{*}$ & $.488^{*}$ & .105 & .072 \\
Clothes (19) & $-.470^{*}$ & .166 & .086 & -.081 & -.183 \\
Fruit (18) & $-.675^{* *}$ & -.017 & .290 & -.105 & -.189 \\
Furniture (16) & $-.724^{* *}$ & .346 & .484 & -.215 & $-.563^{*}$ \\
Musical instruments (15) & $-.719^{* *}$ & .066 & -.062 & -.020 & .207 \\
Sports (12) & $-.842^{* *}$ & .298 & .377 & $-.637 *$ & $-.684^{*}$ \\
Tools (18) & $-.643^{* *}$ & .125 & -.090 & -.162 & -.206 \\
Transport (22) & $-.567^{* *}$ & $.545^{*}$ & .431 & -.318 & $-.526^{*}$ \\
Vegetables (15) & $-.728^{* *}$ & .365 & .177 & -.475 & -.309 \\
\hline
\end{tabular}


How typical is a penguin as a type of bird? You may also think of this as asking: How 'bird-like' is a penguin? You can also compare this to the question: How typical is a robin as a type of bird? Most people would probably say that a robin is more bird-like, or typical, than a penguin.

Participants were instructed to indicate their judgements on a scale ranging from 1 (very typical) to 7 (not very typical). They were also instructed to indicate in a separate field whether they felt that a particular action was not part of the mentioned category.

All the participants rated the typicality of each of the 209 verbs within their respective categories. All the verbs for each individual category were presented on a single page, and participants had to rate all the verbs before moving on to the next category. All the participants completed the same survey. The eight categories were presented in a random order, and the verbs to be rated in each category were also presented in a random order. Before rating the verbs, participants were encouraged to look over all the verbs appearing in the list so that they would (be encouraged to) use the whole scale.

\section{Results}

Typicality ratings Mean typicality ratings (and standard deviations) for verbs within the eight semantic categories are presented in Appendix B. Also provided is the number of participants who rated the response as not belonging to the category.

Correlation analysis: typicality with production frequency and mean rank Mean typicality ratings were correlated with the measures obtained in Experiment 1-namely, production frequency and mean rank. This was conducted to investigate the validity of typicality as a measure of category structure for the verb categories. Spearman's correlation coefficient statistics for the eight categories are presented in Table 7. Typicality significantly correlated with production frequency in seven of the eight categories, where verbs of high production frequency also tended to be rated as highly typical. Typicality also significantly correlated with mean rank in four categories, where verbs produced earlier also tended to be rated as highly typical.

Correlation analysis: typicality with lexical frequency A further correlational analysis was conducted with lexical frequency. Again, the Kučera and Francis (1967) and CELEX databases were employed. The number of observations ranged from as few as 7 (walking) to 18 (breaking). As in Experiment 1, correlations between mean typicality
Table 7 Correlational analysis $\left(r_{\mathrm{s}}\right)$, typicality with production frequency and mean rank

\begin{tabular}{lll}
\hline Category & Typicality $\times$ Production freq & Typicality $\times$ Mean rank \\
\hline Breaking & $-.647^{* *}$ & $.580^{* *}$ \\
Cleaning & $-.487^{* *}$ & .312 \\
Cooking & $-.751^{* *}$ & $.619^{* *}$ \\
Cutting & $-.497^{*}$ & .329 \\
Hitting & $-.617^{* *}$ & $.430^{*}$ \\
Making & $-.487^{* *}$ & $.402^{*}$ \\
Talking & -.164 & .104 \\
Walking & $-.545^{* *}$ & .280 \\
\hline
\end{tabular}

$* p<.05$ (two-tailed)

$* * p<.01$ (two-tailed)

and production frequency and mean rank were conducted again with the reduced number of observations, to allow equal comparison with correlations for lexical frequency. The results of these correlational analyses are presented in Table 8 .

Again, typicality most consistently had a significant relationship with production frequency, whereas only two correlations between typicality and lexical frequency reached significance. It would therefore appear that typicality in verb categories is independent of lexical frequency.

\section{Discussion}

The aims of these experiments were to investigate categorisation and typicality of verbs, in addition to supplying interested readers with a valid set of norms for use when conducting behavioural experiments with verbs.

Similarities between verb and noun categories This study showed that when verbs are used in a category-norming procedure, the response behaviour shows parallels with category norms associated with nouns. First, production frequency and mean rank position within categories generally showed significant correlations, suggesting that responses given by most participants tended to be given earlier. Second, mean typicality ratings correlated significantly with production frequency within categories. Third, task performance at all levels was independent of lexical frequency, as indicated by the failure to observe consistent correlations with any of the other dependent variables (i.e. production frequency, mean rank, and mean typicality). These findings suggest that participants approach categorylisting experiments in the same manner regardless of whether the categories in question relate to verbs or nouns. 
Table 8 Correlations $\left(r_{\mathrm{s}}\right)$ with typicality and other variables (based on verbs with a lexical frequency value)

Typ = mean typicality; Freq $=$ production frequency; $\mathrm{K}-\mathrm{F}=$ Kučera and Francis (1967) frequency count; $\mathrm{CEL}=\mathrm{CELEX}$ frequency count.

${ }^{*} p<.05$ (two-tailed)

$* * p<.01$ (two-tailed)

\begin{tabular}{lllll}
\hline Category & Typ $\times$ Freq & Typ $\times$ Rank & Typ $\times$ K-F & Typ $\times$ CEL \\
\hline Breaking (18) & $-.722^{* *}$ & $.978^{* *}$ & .272 & .172 \\
Cleaning (14) & -.262 & .035 & -.121 & .002 \\
Cooking (11) & $-.758^{* *}$ & $.827^{* *}$ & -.333 & .324 \\
Cutting (9) & $-.741^{*}$ & .633 & -.153 & .250 \\
Hitting (14) & $-.738^{* *}$ & .433 & $.676^{* *}$ & .348 \\
Making (16) & $-.534^{*}$ & $.620^{*}$ & $.623^{*}$ & -.072 \\
Talking (11) & .122 & .409 & -.497 & -.291 \\
Walking (7) & -.643 & .571 & -.393 & -.679 \\
\hline
\end{tabular}

The conclusion that verbs and nouns behave similarly in the category-norming task is reinforced when one considers how these findings compare with those of previous research. As was highlighted earlier, strong correlations have been found between production frequency and mean rank within both noun categories (i.e. Battig \& Montague, 1969) and verb categories (i.e. Hemeren, 1996) in the category-listing task. In addition, it has also been found that typicality correlates significantly with production frequency, but not with lexical frequency (e.g. 1976; Hampton \& Gardiner, 1983; Mervis et al., 1976).

Differences between noun and verb categories Almost inevitably, completing the tasks was more difficult with verbs than with nouns, as indicated by fewer verbs listed than nouns and a higher exclusion rate in the raw data. This may be expected, however, for a number of reasons. These may, most obviously, include the fact that there are simply fewer verbs within the English language, in comparison with nouns, as was highlighted by Miller and Fellbaum (1991) when describing the construction of the lexical database WordNet. This may partly explain why participants frequently responded with modifiers (e.g. adverbs and adjectives); this may have been an attempt to provide a somewhat equivalent number of responses, or at least as many as possible, for each category. Verbs are also more polysemous than nouns. This is indicated by the fact that the 10 noun categories used here displayed a mean number of senses in WordNet of $3(S D=2.16)$, as compared with the 10 verb categories, which showed a mean of $25.3(S D=$ $20.05)$ senses. The greater polysemy associated with verbs could potentially pose problems for participants, in that their responses may frequently diverge from the meaning intended within the experimental procedure. However, this is not supported by the exclusion data, where fewer than $5 \%$ of the exclusions were clearly where participants were using the verb in a different sense than the one intended (e. g. to break up with someone, to make friends). Verbs are also associated with additional syntactic and thematic information, which could be assumed to make their linguistic representations more complex than those of nouns, which are assumed to not be so directly associated with predicating structures (e.g. see Black \& Chiat, 2003, for a review).

Differences between verb categories Differences in conceptual representations may also be one reason why there were variations in behaviour between the verb categories used here. In particular, the categories associated with movement (i.e. jumping, running, and walking) may not be suitable for comparison with the others employed here, since they are fundamentally conceptually different, perhaps at a lower level of hierarchical categorical organisation. It may therefore have been a better comparison if a single category was employed along the lines of 'ways of moving', as in Hemeren (1996). Such a category may therefore be expected to include verbs such as jumping, running, and walking, in addition to others such as swimming, skipping, and so on. Such a category may have proved more consistent when correlational analyses were performed.

There are also possible syntactic and thematic differences to consider. For example, jumping, running, and walking (and talking), are all canonically intransitive verbs, in that they require only a syntactic object and a thematic agent to constitute a complete sentence. In comparison, all the other six categories are canonically transitive, in that they require a syntactic object and a thematic patient or theme, in addition to the subject and agent, in order to form a complete sentence. Therefore, participants may find a category-listing task easier for transitive verbs, since they evoke a wider variety of different situations where they may be applicable. For example, it may be easier to imagine situations where you might break different objects in a variety of different ways, as compared with situations where you might run in different ways.

Organisation of verbs and nouns There have been suggestions that there are fundamentally different principles for the organisation of nouns and verbs (e.g. Graesser, Hopkinson, \& Schmid, 1987; Huttenlocher \& Lui, 1979). There is also extensive evidence-for example, in terms of 
neurolinguistic research - that nouns and verbs are subject to different processing demands, which may again suggest different organisation principles (e.g. Damasio \& Tranel 1993; Luzzatti, Aggujaro, \& Crepaldi, 2006; Shapiro \& Caramazza, 2003). Therefore, it could be argued as to whether category listing and typicality rating are valid experimental tasks for investigating verbs, since they may not enter into categorical relations in the same way that nouns are assumed to. It is not being contended here that differences do not exist with regard to the organisation and representation of nouns and verbs. However, what is being demonstrated is that different organisational principles have the potential to lead to similar patterns of performance in behavioural tasks.

The selection of the experimental categories here for both verbs and nouns was justified with reference to the lexical database WordNet (e.g. Miller \& Fellbaum, 1991), and they were assumed to be equivalent in representing general categories for which participants could list category members. However, other researchers may take issue with the hypothesised levels of categorisation from which verb categories and noun categories were selected. As was stated previously, the noun categories used here were generally consistent with categories used in previous research (e.g. Hampton \& Gardiner, 1983; Rosch et al., 1976). These categories are generally considered to be represented at a 'superordinate level' of categorisation within hierarchical organisation. The superordinate level is immediately above the basic level, which has been suggested to be the most salient level of hierarchical organisation. The basic level is the level at which the greatest semantic information is represented and the level at which the greatest differentiation is present between concepts within the same level (e.g. Rosch, 1978). For example, the concepts fruit and tool are differentiated to a greater extent than are concepts at the next lower level of organisation, such as apple and banana, and hammer and saw, respectively. In comparison, some have suggested that the verb categories employed here would be at the basic level of hierarchical organisation (e.g. Lakoff, 1987; Miller \& Johnson-Laird, 1976). Therefore, noun categories here would primarily elicit production of basic-level nouns, whereas verb categories would primarily elicit production of subordinate- (i.e. lower) level verbs.

These supposed differences in the hierarchical levels of organisation of the noun and verb stimuli could, therefore, account for the differences observed here in terms of the number of responses elicited between word classes. It is not clear, however, whether such terminologies can be applied equivalently between nouns and verbs, since little is currently known with regard to verb organisation, especially in comparison with current knowledge and evidence for noun organisation. If one were to assume that the basic level is conceptually equivalent across nouns and verbs, one would be assuming that the concepts of apple, chair, and car are conceptually equivalent in terms of semantic content (e.g. comparable numbers of semantic features) to the concepts of breaking, talking, and walking. From a purely intuitive sense, it may appear that the concepts apple, chair, and car are more conceptually equivalent to smashing, chatting, and strolling and that the concepts breaking, talking, and walking are more conceptually equivalent to fruit, furniture, and transport. This is therefore an issue worth further consideration and investigation, since it is not clear that the terminology used in the categorisation literature can be applied equivalently when discussing noun and verbs.

Despite the discussion above and the tentative nature of how principles of categorisation and organisation can be applied equivalently between nouns and verbs, what is demonstrated here is that category listing is a valid method for investigating verb organisation. This is argued on the basis of the parallel nature of the uni-directional entailment relations that manifest between nouns and verbs of differing levels of semantic specificity, despite the general feeling that the relational principles are not directly equivalent.

\section{Conclusions}

Given the present findings, the question is posed as to whether typicality is a valid organisational principle of verb categories in semantic memory. This discussion is obviously beyond the scope of the present article, but this may be an issue to be considered in future research. This is especially pertinent given recent attempts to incorporate verbs into representations of semantic memory (e.g. Vigliocco et al., 2004) and also given that explaining typicality effects in behavioural tasks is seen as a crucial test of theories regarding semantic memory. Therefore, it seems reasonable to consider whether typicality effects manifest in behavioural tasks when verbs are used and, if so, whether such effects can be explained adequately within current theories of semantic memory.

In conclusion, it is hoped that these experiments provide a framework for continued investigation of verbs and how they are represented within semantic memory. This by no means makes claim to be as comprehensive as the category norms of Battig and Montague (1969) or subsequent updated and expanded versions of these norms (e.g. Van Overschelde et al., 2004). What this does aim to show is that researchers are able to apply similar methodologies for collecting such norms despite the obvious conceptual, psychological, and linguistic differences between verbs and nouns. 


\section{Appendix A}

Tables 9, 10, 11, 12, 13, 14, 15, 16, 17, 18.

Table 9 Category responses: breaking

\begin{tabular}{|c|c|c|c|}
\hline Response & Production frequency & Mean rank & 1st ranked \\
\hline Dropping & 28 & 3.57 & 3 \\
\hline Smashing & 28 & 1.96 & 22 \\
\hline Snapping & 20 & 4.00 & 3 \\
\hline Crushing & 15 & 4.67 & \\
\hline Hitting & 15 & 5.87 & 2 \\
\hline Ripping & 15 & 6.14 & 1 \\
\hline Tearing & 14 & 6.00 & \\
\hline Throwing & 14 & 5.29 & 1 \\
\hline Bending & 13 & 6.38 & \\
\hline Cracking & 10 & 3.40 & \\
\hline Cutting & 10 & 6.60 & \\
\hline Destroying & 7 & 6.29 & \\
\hline Shattering & 6 & 4.83 & \\
\hline Slicing & 6 & 8.33 & \\
\hline Kicking & 5 & 5.40 & \\
\hline Squashing & 5 & 9.60 & \\
\hline Stamping on & 5 & 8.60 & \\
\hline Chipping & 4 & 4.75 & \\
\hline Bashing & 3 & 7.67 & \\
\hline Burning & 3 & 5.33 & \\
\hline Crashing & 3 & 3.00 & \\
\hline Denting & 3 & 10.67 & \\
\hline Falling & 3 & 8.00 & \\
\hline Forcing & 3 & 8.67 & \\
\hline Jumping on & 3 & 4.33 & 1 \\
\hline Pulling apart & 3 & 6.00 & \\
\hline Pulling & 3 & 8.00 & \\
\hline Shredding & 3 & 9.33 & \\
\hline Splintering & 3 & 7.33 & \\
\hline Splitting & 3 & 7.67 & \\
\hline
\end{tabular}

Production frequency of $2(N=10)$ : banging, exploding, fracturing, freezing, hammering, knocking, mashing, punching (1st ranked: 1), squeezing, submerging. Production frequency of $1(N=43)$

Table 10 Category responses: cleaning

\begin{tabular}{lccc}
\hline Response & Production frequency & Mean rank & 1st ranked \\
\hline Washing & 30 & 3.97 & 4 \\
Scrubbing & 30 & 2.53 & 15 \\
Wiping & 22 & 4.00 & 4 \\
Brushing & 21 & 5.76 & \\
Polishing & 21 & 4.00 & 5 \\
Hoovering & 20 & 6.00 &
\end{tabular}

Table 10 (continued)

\begin{tabular}{|c|c|c|c|}
\hline Response & Production frequency & Mean rank & 1 st ranked \\
\hline Mopping & 19 & 7.16 & \\
\hline Dusting & 17 & 5.47 & 1 \\
\hline Rubbing & 14 & 6.29 & 2 \\
\hline Rinsing & 11 & 5.55 & \\
\hline Soaking & 10 & 6.30 & \\
\hline Sweeping & 10 & 7.90 & \\
\hline Spraying & 9 & 7.33 & 1 \\
\hline Bleaching & 7 & 5.86 & \\
\hline Cleansing & 6 & 6.17 & \\
\hline Scouring & 6 & 6.17 & \\
\hline Shining & 6 & 6.00 & 2 \\
\hline Bathing & 5 & 8.60 & \\
\hline Hosing & 5 & 8.60 & \\
\hline Shampoo & 5 & 7.40 & \\
\hline Steaming & 5 & 7.40 & \\
\hline Drying & 4 & 7.25 & \\
\hline Scraping & 4 & 10.25 & \\
\hline Showering & 4 & 9.75 & \\
\hline Sterilising & 4 & 8.25 & \\
\hline Vacuuming & 4 & 9.50 & \\
\hline Dabbing & 3 & 12.00 & \\
\hline Disinfecting & 3 & 5.00 & \\
\hline Dry cleaning & 3 & 6.00 & \\
\hline Lathering & 3 & 5.33 & \\
\hline
\end{tabular}

Production frequency of $2(N=9)$ : airing, beating, boiling, flossing, shaking, soaping, swilling, tidying, waxing. Production frequency of 1 $(N=28)$

Table 11 Category responses: cooking

\begin{tabular}{lccc}
\hline Response & Production frequency & Mean rank & 1st ranked \\
\hline Frying & 32 & 2.63 & 11 \\
Boiling & 31 & 3.58 & 7 \\
Grilling & 31 & 5.42 & 1 \\
Baking & 30 & 3.23 & 11 \\
Roasting & 23 & 5.57 & \\
Steaming & 21 & 6.10 & \\
Microwaving & 20 & 7.55 & \\
Barbequing & 15 & 7.67 & \\
Simmering & 14 & 6.00 & \\
Poaching & 12 & 6.58 & \\
Toasting & 12 & 8.50 & \\
Heating & 9 & 7.11 & \\
Sautéing & 8 & 6.63 & \\
Stir frying & 8 & 5.50 & 1 \\
Burning & 7 & 8.71 & \\
Blanching & 5 & 6.40 & 1 \\
Melting & 5 & 8.60 & 1 \\
& & &
\end{tabular}


Table 11 (continued)

\begin{tabular}{lccc}
\hline Response & Production frequency & Mean rank & 1st ranked \\
\hline Mixing & 5 & 11.40 & \\
Stewing & 5 & 7.00 & \\
Griddling & 4 & 6.75 & \\
Searing & 4 & 7.75 & \\
Slow cooking & 4 & 7.00 & 1 \\
Braising & 3 & 8.67 & \\
Char-grilling & 3 & 7.33 & \\
Chopping & 3 & 12.67 & \\
Deep frying & 3 & 5.00 & \\
Freezing & 3 & 10.00 & \\
Scrambling & 3 & 14.67 & \\
& & & \\
\hline
\end{tabular}

Production frequency of $2(N=8)$ : beating, broiling, casseroling, mashing, rotissering, shallow frying (1), spit roasting, whisking. Production frequency of $1(N=24)$. Exclusions with frequency $\geq 5$ : oven (5)

Table 12 Category responses: cutting

\begin{tabular}{lccc}
\hline Response & Production frequency & Mean rank & 1st ranked \\
\hline Slicing & 22 & 1.91 & 11 \\
Chopping & 21 & 2.29 & 7 \\
Sawing & 20 & 4.10 & 3 \\
Dicing & 13 & 4.23 & \\
Stabbing & 10 & 4.00 & \\
Tearing & 9 & 3.33 & 1 \\
Hacking & 8 & 3.38 & 1 \\
Ripping & 7 & 3.57 & 2 \\
Snipping & 5 & 4.00 & \\
Scissoring & 4 & 6.00 & 1 \\
Slashing & 4 & 2.50 & 2 \\
Snapping & 4 & 5.75 & 1 \\
Splitting & 4 & 6.00 & \\
Trimming & 4 & 7.00 & \\
Carving & 3 & 3.33 & \\
Grating & 3 & 5.00 & \\
Piercing & 3 & 5.33 & \\
Severing & 3 & 4.33 & \\
\hline
\end{tabular}

Production frequency of $2(N=9)$ : dividing, incising, knifing, mincing, scoring (1), segmenting, shaving, shearing, shredding. Production frequency of $1(N=31)$. Exclusions with frequency $\geq 5$ : scissors/using scissors/with scissors (combined frequency of 11), knife/using a knife/with a knife (10)

Table 13 Category responses: hitting

\begin{tabular}{lccc}
\hline Response & Production frequency & Mean rank & 1st ranked \\
\hline Punching & 31 & 2.00 & 16 \\
Slapping & 24 & 3.67 & 4
\end{tabular}

Table 13 (continued)

\begin{tabular}{|c|c|c|c|}
\hline Response & Production frequency & Mean rank & 1st ranked \\
\hline Kicking & 16 & 3.81 & \\
\hline Smacking & 12 & 3.50 & 3 \\
\hline Bashing & 8 & 4.50 & 2 \\
\hline Crashing & 8 & 6.25 & \\
\hline Hammering & 8 & 3.88 & 3 \\
\hline Smashing & 8 & 5.88 & \\
\hline Banging & 7 & 4.29 & 1 \\
\hline Thumping & 7 & 5.00 & \\
\hline Whacking & 7 & 6.71 & 1 \\
\hline Elbowing & 6 & 7.17 & \\
\hline Head butting & 6 & 5.33 & \\
\hline Walloping & 6 & 6.00 & \\
\hline Colliding & 5 & 7.20 & \\
\hline Jabbing & 5 & 4.00 & \\
\hline Beating & 4 & 6.50 & 1 \\
\hline Tapping & 4 & 4.25 & 1 \\
\hline Batting & 3 & 1.33 & 2 \\
\hline Flicking & 3 & 6.33 & \\
\hline Knocking & 3 & 7.33 & \\
\hline Nudging & 3 & 6.33 & \\
\hline Poking & 3 & 6.00 & \\
\hline Pushing & 3 & 8.00 & \\
\hline Striking & 3 & 3.00 & \\
\hline Throwing & 3 & 8.33 & \\
\hline
\end{tabular}

Production frequency of $2(N=15)$ : battering, blowing, brushing, bumping, clubbing, digging, falling, hooking, kneeing, patting, pounding, pummelling, swinging, swiping, whipping. Production frequency of $1(N=35)$. Exclusions with frequency $\geq 5$ : hard (9)

Table 14 Category responses: jumping

\begin{tabular}{lccc}
\hline Response & Production frequency & Mean rank & 1st ranked \\
\hline Hopping & 22 & 2.64 & 7 \\
Leaping & 17 & 3.18 & 8 \\
Long jump & 16 & 3.31 & 1 \\
Skipping & 16 & 3.50 & \\
High jumping & 15 & 3.33 & 6 \\
Bouncing & 14 & 4.00 & 2 \\
Star jumping & 11 & 3.45 & 2 \\
Bounding & 10 & 4.70 & 1 \\
Diving & 9 & 4.33 & 1 \\
Springing & 9 & 4.33 & 1 \\
Triple jump & 7 & 4.57 & \\
Bungee jump & 5 & 2.40 & 2 \\
Trampolining & 5 & 5.20 & \\
Vaulting & 5 & 4.40 & 2 \\
Leapfrog & 3 & 6.67 &
\end{tabular}


Table 14 (continued)

\begin{tabular}{lccc}
\hline Response & Production frequency & Mean rank & 1st ranked \\
\hline Pike jump & 3 & 6.33 \\
Show jumping & 3 & 6.67 \\
Skydiving & 3 & 5.00
\end{tabular}

Production frequency of $2(N=6)$ : flinging, flipping, running, somersaulting (1), standing jumping, tuck jumping. Production frequency of $1(N=24)$. Exclusions with frequency $\geq 5$ : up/up and down (7)

Table 15 Category responses: making

\begin{tabular}{|c|c|c|c|}
\hline Response & Production frequency & Mean rank & 1st ranked \\
\hline Baking & 23 & 3.30 & 6 \\
\hline Building & 21 & 4.00 & 3 \\
\hline Cooking & 19 & 4.42 & 6 \\
\hline Drawing & 17 & 6.35 & \\
\hline Gluing & 17 & 3.47 & 6 \\
\hline Painting & 16 & 5.94 & \\
\hline Creating & 12 & 5.17 & 1 \\
\hline Sewing & 9 & 3.78 & 1 \\
\hline Sticking & 9 & 4.00 & 2 \\
\hline Moulding & 8 & 5.00 & 1 \\
\hline Constructing & 8 & 4.88 & 1 \\
\hline Carving & 6 & 6.17 & \\
\hline Designing & 6 & 5.83 & \\
\hline Mixing & 6 & 7.50 & 1 \\
\hline Sculpting & 6 & 6.33 & 1 \\
\hline Assembling & 5 & 3.80 & \\
\hline Hammering & 5 & 8.80 & \\
\hline Knitting & 5 & 3.80 & 1 \\
\hline Writing & 5 & 11.00 & \\
\hline Cutting & 4 & 4.75 & 1 \\
\hline Printing & 4 & 4.25 & \\
\hline Sawing & 4 & 7.75 & \\
\hline Crafting & 3 & 5.00 & 1 \\
\hline Fixing & 3 & 6.00 & \\
\hline Folding & 3 & 7.00 & \\
\hline Inventing & 3 & 7.67 & \\
\hline Joining & 3 & 2.67 & 1 \\
\hline Manufacturing & 3 & 8.67 & \\
\hline Recording & 3 & 5.00 & \\
\hline Typing & 3 & 9.00 & \\
\hline Welding & 3 & 7.33 & 1 \\
\hline
\end{tabular}

Production frequency of $2(N=12)$ : bending, blending, boiling, colouring, composing, computing, frying, growing, producing, stacking, stirring (1), stitching. Production frequency of $1(N=47)$
Table 16 Category responses: running

\begin{tabular}{lccc}
\hline Response & Production frequency & Mean rank & 1st ranked \\
\hline Jogging & 31 & 1.58 & 18 \\
Sprinting & 31 & 1.71 & 13 \\
Racing & 8 & 3.38 & \\
Marathoning & 6 & 3.00 & \\
Dashing & 4 & 2.75 & \\
Striding & 3 & 3.67 & \\
\hline
\end{tabular}

Production Frequency of $2(N=7)$ : bounding, chasing, galloping, legging it, rushing, training, trotting (1). Production frequency of 1 $(N=12)$. Exclusions with frequency $\geq 5$ : slow/slowly (14), fast (10), quick/quickly (6), backwards (5), cross country (5), steady/steadily (5)

Table 17 Category responses: talking

\begin{tabular}{lccc}
\hline Response & Production frequency & Mean rank & 1st ranked \\
\hline Shouting & 26 & 2.85 & 5 \\
Whispering & 26 & 2.96 & 8 \\
Chatting & 14 & 2.79 & 8 \\
Speaking & 10 & 4.30 & 4 \\
Conversing & 9 & 6.00 & \\
Discussing & 9 & 6.33 & \\
Gossiping & 8 & 4.75 & \\
Yelling & 8 & 6.63 & \\
Screaming & 7 & 5.14 & \\
Arguing & 7 & 3.71 & \\
Signing & 7 & 6.71 & \\
Mumbling & 5 & 4.80 & \\
Answering & 4 & 2.25 & \\
Chattering & 4 & 9.25 & 3 \\
Debating & 4 & 9.50 & \\
Lecturing & 4 & 5.25 & \\
Questioning & 4 & 5.50 & \\
Nattering & 3 & 4.00 & \\
Saying & 3 & 6.67 & \\
Stating & 3 & 6.33 & \\
Stuttering & 3 & 4.67 & \\
& & &
\end{tabular}

Production frequency of $2(N=6)$ : asking, babbling, commanding, croaking, exclaiming, explaining, gesturing (1), instructing, joking, reading, singing, suggesting, swearing, teaching, telling, texting. Production frequency of $1(N=45)$. Exclusions with frequency $\geq 5$ : loudly (11), quietly (9), slowly (9), fast (6)

Table 18 Category responses: walking

\begin{tabular}{lccc}
\hline Response & Production frequency & Mean rank & 1st ranked \\
\hline Strolling & 15 & 2.93 & 7 \\
Ambling & 12 & 2.58 & 1 \\
Striding & 10 & 2.80 & 6
\end{tabular}


Table 18 (continued)

\begin{tabular}{llcc}
\hline Response & Production frequency & Mean rank & 1st ranked \\
\hline Power-walking & 9 & 2.89 & 2 \\
Hiking & 8 & 5.75 & 1 \\
Sauntering & 8 & 3.75 & 2 \\
Wandering & 8 & 3.63 & \\
Limping & 7 & 4.29 & 1 \\
Meandering & 7 & 4.86 & \\
Dawdling & 6 & 3.50 & \\
Marching & 6 & 4.17 & 1 \\
Shuffling & 6 & 4.17 & \\
Jogging & 5 & 5.40 & 1 \\
Pacing & 5 & 4.80 & 1 \\
Running & 5 & 4.60 & \\
Staggering & 5 & 6.00 & \\
Tip toeing & 5 & 7.00 & \\
Rambling & 4 & 7.00 & \\
Stepping & 4 & 7.75 & \\
Fell walking & 3 & 3.67 & 1 \\
Hopping & 3 & 5.67 & 1 \\
Moonwalking & 3 & 3.00 & 1 \\
Speed walking & 3 & 1.00 & 3 \\
Trekking & 3 & 6.00 & 1 \\
Trotting & 3 & 3.33 & \\
& & & \\
\hline
\end{tabular}

Production frequency of $2(N=7)$ : creeping, hobbling, mincing, skipping, stomping, strutting, stumbling. Production frequency of 1 $(N=36)$. Exclusions with frequency $\geq 5$ : slow/slowly (15), quick/ quickly (8), backwards (7), forwards (6)

\section{Appendix B}

Tables 19, 20, 21, 22, 23, 24, 25, 26.

Table 19 Typicality ratings: breaking

\begin{tabular}{lccc}
\hline Response & Mean typicality & \multicolumn{1}{l}{$S D$} & Not in category \\
\hline Snapping & 1.47 & 0.853 & 0 \\
Smashing & 1.72 & 1.093 & 0 \\
Dropping & 1.94 & 1.171 & 2 \\
Destroying & 2.20 & 1.654 & 7 \\
Ripping & 2.24 & 1.335 & 1 \\
Shattering & 2.25 & 1.398 & 0 \\
Cracking & 2.28 & 1.262 & 0 \\
Crushing & 2.41 & 1.282 & 1 \\
Bashing & 2.45 & 1.353 & 1 \\
Pulling apart & 2.46 & 1.325 & 0 \\
Tearing & 2.51 & 1.322 & 2 \\
Cutting & 2.69 & 1.619 & 2 \\
Hitting & 2.73 & 1.359 & 4 \\
Stamping on & 2.82 & 1.633 & 1
\end{tabular}

Table 19 (continued)

\begin{tabular}{lccc}
\hline Response & Mean typicality & \multicolumn{1}{l}{$S D$} & Not in category \\
\hline Burning & 3.09 & 1.756 & 3 \\
Squashing & 3.10 & 1.528 & 2 \\
Splitting & 3.18 & 1.373 & 2 \\
Crashing & 3.24 & 1.682 & 5 \\
Jumping on & 3.30 & 1.801 & 2 \\
Kicking & 3.47 & 1.716 & 3 \\
Chipping & 3.53 & 1.574 & 4 \\
Throwing & 3.56 & 1.767 & 7 \\
Bending & 3.70 & 1.854 & 3 \\
Falling & 3.74 & 1.833 & 15 \\
Slicing & 3.75 & 1.766 & 2 \\
Denting & 3.79 & 1.651 & 4 \\
Shredding & 4.00 & 1.627 & 2 \\
Forcing & 4.05 & 1.834 & 8 \\
Splintering & 4.21 & 1.594 & 5 \\
Pulling & 4.37 & 1.805 & 5 \\
\hline
\end{tabular}

Table 20 Typicality ratings: cleaning

\begin{tabular}{|c|c|c|c|}
\hline Response & Mean typicality & $S D$ & Not in category \\
\hline Washing & 1.17 & 0.509 & 0 \\
\hline Wiping & 1.17 & 0.375 & 0 \\
\hline Hoovering & 1.40 & 0.664 & 0 \\
\hline Vacuuming & 1.41 & 0.722 & 0 \\
\hline Sweeping & 1.48 & 0.685 & 0 \\
\hline Mopping & 1.56 & 0.803 & 0 \\
\hline Dusting & 1.59 & 0.979 & 0 \\
\hline Scrubbing & 1.63 & 0.954 & 0 \\
\hline Showering & 1.81 & 1.255 & 1 \\
\hline Bathing & 1.93 & 1.283 & 1 \\
\hline Disinfecting & 2.02 & 1.186 & 0 \\
\hline Polishing & 2.06 & 1.225 & 0 \\
\hline Shampoo & 2.07 & 1.290 & 1 \\
\hline Rinsing & 2.13 & 1.325 & 0 \\
\hline Scouring & 2.27 & 1.415 & 0 \\
\hline Cleansing & 2.37 & 1.568 & 2 \\
\hline Bleaching & 2.40 & 1.437 & 0 \\
\hline Brushing & 2.49 & 1.609 & 6 \\
\hline Dry cleaning & 2.53 & 1.591 & 1 \\
\hline Hosing & 2.56 & 1.317 & 0 \\
\hline Soaking & 2.61 & 1.496 & 1 \\
\hline Sterilising & 2.75 & 1.663 & 0 \\
\hline Dabbing & 2.97 & 1.323 & 0 \\
\hline Rubbing & 3.04 & 1.551 & 3 \\
\hline Shining & 3.06 & 1.448 & 2 \\
\hline Lathering & 3.13 & 1.647 & 4 \\
\hline
\end{tabular}


Table 20 (continued)

\begin{tabular}{lccc}
\hline Response & Mean typicality & $S D$ & Not in category \\
\hline Spraying & 3.17 & 1.564 & 2 \\
Scraping & 3.48 & 1.418 & 2 \\
Steaming & 3.68 & 1.677 & 3 \\
Drying & 4.24 & 1.789 & 20 \\
\hline
\end{tabular}

Table 21 Typicality ratings: cooking

\begin{tabular}{|c|c|c|c|}
\hline Response & Mean typicality & $S D$ & Not in category \\
\hline Frying & 1.26 & 0.612 & 0 \\
\hline Grilling & 1.33 & 0.665 & 0 \\
\hline Roasting & 1.38 & 0.809 & 0 \\
\hline Baking & 1.45 & 0.840 & 0 \\
\hline Boiling & 1.59 & 0.948 & 0 \\
\hline Toasting & 1.62 & 0.912 & 0 \\
\hline Stewing & 1.69 & 0.944 & 0 \\
\hline Microwaving & 1.73 & 1.085 & 1 \\
\hline Barbequing & 1.76 & 1.170 & 0 \\
\hline Stir-frying & 1.78 & 1.050 & 0 \\
\hline Simmering & 1.88 & 1.151 & 1 \\
\hline Slow cooking & 2.06 & 1.296 & 0 \\
\hline Heating & 2.15 & 1.452 & 0 \\
\hline Steaming & 2.21 & 1.315 & 0 \\
\hline Poaching & 2.22 & 1.412 & 0 \\
\hline Scrambling & 2.29 & 1.339 & 0 \\
\hline Deep frying & 2.37 & 1.495 & 0 \\
\hline Sautéing & 2.72 & 1.834 & 1 \\
\hline Char-grilling & 2.75 & 1.793 & 0 \\
\hline Searing & 2.79 & 1.734 & 3 \\
\hline Braising & 2.81 & 1.793 & 1 \\
\hline Chopping & 2.96 & 1.809 & 17 \\
\hline Mixing & 3.07 & 1.657 & 13 \\
\hline Griddling & 3.11 & 1.863 & 2 \\
\hline Melting & 3.26 & 1.793 & 3 \\
\hline Blanching & 3.38 & 1.970 & 0 \\
\hline Burning & 4.01 & 1.964 & 10 \\
\hline Freezing & 4.96 & 1.962 & 28 \\
\hline
\end{tabular}

Table 22 Typicality ratings: cutting

\begin{tabular}{lccc}
\hline Response & Mean Typicality & $S D$ & Not in Category \\
\hline Slicing & 1.24 & 0.530 & 0 \\
Chopping & 1.29 & 0.669 & 0 \\
Dicing & 1.87 & 1.200 & 0 \\
Sawing & 1.92 & 1.096 & 0
\end{tabular}

Table 22 (continued)

\begin{tabular}{lccc}
\hline Response & Mean Typicality & \multicolumn{1}{l}{$S D$} & Not in Category \\
\hline Trimming & 1.93 & 1.101 & 0 \\
Scissoring & 2.11 & 1.568 & 1 \\
Snipping & 2.14 & 1.178 & 0 \\
Carving & 2.18 & 1.458 & 0 \\
Slashing & 2.44 & 1.411 & 0 \\
Severing & 2.60 & 1.582 & 1 \\
Hacking & 3.07 & 1.531 & 1 \\
Tearing & 3.09 & 1.847 & 8 \\
Ripping & 3.09 & 1.704 & 11 \\
Splitting & 3.63 & 1.810 & 5 \\
Grating & 3.64 & 1.801 & 2 \\
Piercing & 3.94 & 1.780 & 9 \\
Stabbing & 3.97 & 1.883 & 6 \\
Snapping & 4.11 & 1.735 & 11 \\
\hline
\end{tabular}

Table 23 Typicality ratings: hitting

\begin{tabular}{|c|c|c|c|}
\hline Response & Mean typicality & $S D$ & Not in category \\
\hline Punching & 1.21 & 0.722 & 0 \\
\hline Slapping & 1.72 & 0.999 & 0 \\
\hline Smacking & 1.75 & 1.132 & 0 \\
\hline Thumping & 1.83 & 1.192 & 1 \\
\hline Whacking & 2.05 & 1.410 & 0 \\
\hline Striking & 2.07 & 1.381 & 0 \\
\hline Beating & 2.09 & 1.326 & 2 \\
\hline Bashing & 2.26 & 1.411 & 2 \\
\hline Whalloping & 2.32 & 1.663 & 2 \\
\hline Hammering & 2.59 & 1.649 & 0 \\
\hline Banging & 2.69 & 1.542 & 2 \\
\hline Colliding & 2.73 & 1.636 & 1 \\
\hline Elbowing & 2.74 & 1.262 & 1 \\
\hline Smashing & 2.80 & 1.455 & 5 \\
\hline Kicking & 2.91 & 1.936 & 6 \\
\hline Knocking & 2.99 & 1.735 & 1 \\
\hline Batting & 3.04 & 1.795 & 3 \\
\hline Jabbing & 3.09 & 1.530 & 1 \\
\hline Pushing & 3.29 & 1.753 & 6 \\
\hline Head-butting & 3.37 & 2.009 & 1 \\
\hline Tapping & 3.47 & 1.834 & 2 \\
\hline Crashing & 3.76 & 1.913 & 9 \\
\hline Flicking & 4.17 & 1.567 & 4 \\
\hline Nudging & 4.30 & 1.748 & 4 \\
\hline Poking & 4.31 & 1.743 & 6 \\
\hline Throwing & 4.68 & 2.008 & 26 \\
\hline
\end{tabular}


Table 24 Typicality ratings: making

\begin{tabular}{|c|c|c|c|}
\hline Response & Mean typicality & $S D$ & Not in category \\
\hline Assembling & 1.56 & 0.907 & 0 \\
\hline Constructing & 1.60 & 1.017 & 0 \\
\hline Cooking & 1.63 & 1.033 & 0 \\
\hline Creating & 1.64 & 1.092 & 1 \\
\hline Building & 1.66 & 1.085 & 0 \\
\hline Manufacturing & 1.71 & 1.095 & 0 \\
\hline Baking & 1.73 & 0.966 & 0 \\
\hline Moulding & 2.05 & 1.323 & 0 \\
\hline Sculpting & 2.12 & 1.588 & 0 \\
\hline Crafting & 2.21 & 1.431 & 1 \\
\hline Painting & 2.39 & 1.346 & 3 \\
\hline Knitting & 2.44 & 1.638 & 0 \\
\hline Sewing & 2.49 & 1.419 & 0 \\
\hline Joining & 2.52 & 1.621 & 0 \\
\hline Drawing & 2.55 & 1.459 & 3 \\
\hline Inventing & 2.63 & 1.668 & 2 \\
\hline Designing & 2.64 & 1.480 & 4 \\
\hline Carving & 2.78 & 1.635 & 1 \\
\hline Sticking & 2.79 & 1.591 & 2 \\
\hline Writing & 2.89 & 1.647 & 3 \\
\hline Welding & 2.95 & 1.815 & 0 \\
\hline Gluing & 3.01 & 1.662 & 0 \\
\hline Recording & 3.14 & 1.708 & 3 \\
\hline Mixing & 3.17 & 1.697 & 1 \\
\hline Printing & 3.19 & 1.629 & 4 \\
\hline Typing & 3.26 & 1.728 & 5 \\
\hline Hammering & 3.29 & 1.654 & 6 \\
\hline Cutting & 3.41 & 1.728 & 4 \\
\hline Fixing & 3.49 & 1.762 & 14 \\
\hline Sawing & 3.64 & 1.597 & 6 \\
\hline Folding & 3.69 & 1.673 & 5 \\
\hline
\end{tabular}

Table 25 Typicality ratings: talking

\begin{tabular}{lccc}
\hline Response & Mean Typicality & $S D$ & Not in Category \\
\hline Speaking & 1.10 & 0.520 & 1 \\
Chatting & 1.20 & 0.508 & 0 \\
Saying & 1.31 & 0.706 & 2 \\
Discussing & 1.51 & 0.743 & 1 \\
Conversing & 1.65 & 1.132 & 2 \\
Chattering & 1.81 & 1.132 & 0 \\
Gossiping & 1.97 & 1.096 & 2 \\
Answering & 2.05 & 1.146 & 3 \\
Nattering & 2.09 & 1.187 & 0 \\
Questioning & 2.23 & 1.136 & 2 \\
Whispering & 2.25 & 1.094 & 0 \\
Mumbling & 2.48 & 1.167 & 0
\end{tabular}

Table 25 (continued)

\begin{tabular}{lccc}
\hline Response & Mean Typicality & $S D$ & Not in Category \\
\hline Debating & 2.49 & 1.063 & 3 \\
Stating & 2.55 & 1.402 & 3 \\
Arguing & 2.68 & 1.254 & 2 \\
Lecturing & 2.95 & 1.396 & 1 \\
Shouting & 3.04 & 1.538 & 3 \\
Yelling & 3.42 & 1.577 & 2 \\
Stuttering & 4.01 & 1.686 & 0 \\
Screaming & 4.17 & 1.745 & 8 \\
Signing & 4.55 & 1.848 & 3 \\
\hline
\end{tabular}

Table 26 Typicality ratings: walking

\begin{tabular}{|c|c|c|c|}
\hline Response & Mean Typicality & $S D$ & Not in Category \\
\hline Strolling & 1.56 & 0.981 & 0 \\
\hline Wandering & 2.02 & 1.233 & 1 \\
\hline Striding & 2.21 & 1.300 & 0 \\
\hline Hiking & 2.37 & 1.334 & 0 \\
\hline Dawdling & 2.43 & 1.322 & 1 \\
\hline Speed walking & 2.52 & 1.572 & 0 \\
\hline Power-walking & 2.59 & 1.685 & 0 \\
\hline Stepping & 2.59 & 1.652 & 2 \\
\hline Trekking & 2.61 & 1.358 & 0 \\
\hline Pacing & 2.70 & 1.488 & 0 \\
\hline Ambling & 2.74 & 1.547 & 0 \\
\hline Sauntering & 2.75 & 1.438 & 0 \\
\hline Meandering & 3.02 & 1.653 & 0 \\
\hline Running & 3.11 & 2.120 & 20 \\
\hline Staggering & 3.11 & 1.414 & 0 \\
\hline Marching & 3.15 & 1.788 & 0 \\
\hline Fell-walking & 3.19 & 1.701 & 1 \\
\hline Jogging & 3.38 & 1.878 & 11 \\
\hline Rambling & 3.50 & 1.689 & 1 \\
\hline Limping & 3.58 & 1.710 & 1 \\
\hline Tip-toeing & 3.75 & 1.777 & 0 \\
\hline Shuffling & 3.78 & 1.689 & 1 \\
\hline Trotting & 4.45 & 1.633 & 5 \\
\hline Hopping & 5.18 & 1.497 & 13 \\
\hline Moonwalking & 5.47 & 1.689 & 8 \\
\hline
\end{tabular}

\section{References}

Battig, W. F., \& Montague, W. E. (1969). Category norms for verbal items in 56 categories: A replication and extension of the Connecticut category norms. Journal of Experimental Psychology, 80(3), 1-46. doi:10.1037/h0027577 
Black, M., \& Chiat, S. (2003). Noun-verb dissociations: A multifaceted phenomenon. Journal of Neurolinguistics, 16, 231-250.

Capitani, E., Laiacona, M., \& Barbarotto, R. (1999). Gender affects word retrieval of certain categories in semantic fluency tasks. Cortex, 35, 273-278.

Caramazza, A., \& Shelton, J. (1998). Domain-specific knowledge systems in the brain: The animate-inanimate distinction. Journal of Cognitive Neuroscience, 10, 1-34.

Coltheart, M. (1981). The MRC psycholinguistic database. The Quarterly Journal of Experimental Psychology, 33A, 497-505.

Conroy, P., Sage, K., \& Lambon Ralph, M. (2006). Towards theorydriven therapies for aphasic verb impairments: A review of current theory and practice. Aphasiology, 20, 1159-1185. doi:10.1080/02687030600792009

Damasio, A. R., \& Tranel, D. (1993). Nouns and verbs are retrieved with differently distributed neural systems. Proceedings of the National Academy of Sciences, 90, 4957-4960.

Graesser, A. C., Hopkinson, P. L., \& Schmid, C. (1987). Differences in interconcept organization between nouns and verbs. Journal of Memory and Language, 26, 242-253.

Hampton, J. A., \& Gardiner, M. M. (1983). Measures of internal category structure: A correlational analysis of normative data. British Journal of Psychology, 74, 491-516.

Hemeren, P. E. (1996). Frequency, ordinal position and semantic distance as measures of cross-cultural stability and hierarchies for action verbs. Acta Psychologica, 91, 39-66.

Huttenlocher, J., \& Lui, F. (1979). Semantic organization of some simple nouns and verbs. Journal of Verbal Learning and Verbal Behavior, 18, 141-162.

Kiran, S., \& Thompson, C. K. (2003). The role of semantic complexity in treatment of naming deficits: Training semantic categories in fluent aphasia by controlling exemplar typicality. Journal of Speech, Language, and Hearing Research, 46, 773787. doi:10.1016/50093-934X(03)00064-6

Kučera, H., \& Francis, W. N. (1967). Computational analysis of presentday American English. Providence: Brown University Press.

Laiacona, M., Barbarotto, R., \& Capitani, E. (2006). Human evolution and the brain representation of semantic knowledge: Is there a role for gender differences? Evolution and Human Behavior, 27, 158-168. doi:10.1016/j.evolhumbehav.2005.08.002

Lakoff, G. (1987). Women, fire, and dangerous things: What categories reveal about the mind. Chicago: University of Chicago Press.

Levin, B. (1993). English verb classes and alternations: A preliminary investigation. Chicago: University of Chicago Press.
Luzzatti, C., Aggujaro, S., \& Crepaldi, D. (2006). Verb-noun double dissociation in aphasia: Theoretical and neuroanatomial foundations. Cortex, 42, 875-883.

McRae, K., Cree, G. S., Seidenberg, M. S., \& McNorgan, C. (2005). Semantic feature production norms for a large set of living and nonliving things. Behavior Research Methods, Instruments, \& Computers, 37, 547-559.

Mervis, C. B., Catlin, J., \& Rosch, E. (1976). Relationships among goodness-of-example, category norms, and word frequency. Bulletin of the Psychonomic Society, 7, 283-284.

Miller, G. A., \& Fellbaum, C. (1991). Semantic networks of English. Cognition, 41, 197-229.

Miller, G. A., \& Johnson-Laird, P. N. (1976). Language and perception. Cambridge: Cambridge University Press.

Riddoch, M. J., \& Humphreys, G. W. (1987). A case of integrative visual agnosia. Brain, 110, 1431-1462.

Rosch, E. (1978). Principles of categorization. In E. Rosch \& B. B. Lloyd (Eds.), Cognition and categorization (pp. 27-48). Hillsdale: Erlbaum.

Rosch, E., \& Mervis, C. B. (1975). Family resemblances: Studies in the internal structure of categories. Cognitive Psychology, 7, 573-605.

Rosch, E., Mervis, C. B., Gray, W. D., Johnson, D. M., \& BoyesBraem, P. (1976). Basic objects in natural categories. Cognitive Psychology, 8, 382-439.

Shapiro, K., \& Caramazza, A. (2003). The representation of grammatical categories in the brain. Trends in Cognitive Sciences, 7, 201-206.

Smith, E. E., Shoben, E. J., \& Rips, L. J. (1974). Structure and process in semantic memory: A featural model for semantic decisions. Psychological Review, 81, 214-241. doi:10.1037/h0036351

Van Overschelde, J. P., Rawson, K. A., \& Dunlosky, J. (2004). Category norms: An updated and expanded version of the Battig and Montague (1969) norms. Journal of Memory and Language, 50, 289-335. doi:10.1016/j.jml.2003.10.003

Vigliocco, G., Vinson, D. P., Lewis, W., \& Garrett, M. F. (2004). Representing the meanings of object and action words: The featural and unitary semantic space hypothesis. Cognitive Psychology, 48, 422-288. doi:10.1016/j.cogpsych.2003.09.001

Vinson, D. P., Vigliocco, G., Cappa, S., \& Siri, S. (2003). The breakdown of semantic knowledge: Insights from a statistical model of meaning representation. Brain and Language, 86, 347365. doi:10.1016/50093-934X(03)00144-5

Warrington, E. K., \& McCarthy, R. A. (1987). Categories of knowledge: Further fractionations and an attempted integration. Brain, 110, 1273-1296. 